\title{
Aeroelastic stability analysis of aircraft wings with initial
}

\section{curvature}

\author{
M.R. Amoozgar ${ }^{1}$, S.A. Fazelzadeh ${ }^{2}$, H. Haddad Khodaparast ${ }^{3}$, M.I. Friswell ${ }^{4}$, J. E. Cooper ${ }^{5}$ \\ ${ }^{1}$ School of Computing and Engineering, University of Huddersfield, Huddersfield, HD1 3DH, United Kingdom \\ ${ }^{2}$ School of Mechanical Engineering, Shiraz University, Shiraz 71963-16548, Iran \\ ${ }^{3,4}$ College of Engineering, Swansea University, Swansea, Wales SA2 8PP, United Kingdom \\ ${ }^{5}$ Department of Aerospace Engineering, Bristol University, Bristol, BS8 1TR, United Kingdom
}

In this study, the aeroelastic instability of a wing with an initial out-of-plane curvature is determined. The structural dynamics of the wing is modelled by using the geometrically exact beam equations, and the aerodynamic loads are determined using an incompressible unsteady aerodynamic model. The wing is considered to have initial out-of-plane curvature, and the effect of the curvature on the flutter velocity and flutter frequency of the wing is determined. Two curved wing cases are considered here. In the first case, the length of the wing is assumed to be constant and therefore, as the wing is curved, the projected area of the wing decreases. In the second case, the wing is assumed to have a constant projected area and therefore different curvature angles result from different wing lengths. When the wing is designed to have an initial out-of-plane curvature, the wing dynamics change, and therefore the aeroelastic stability of the curved wing is also affected. It is shown that as the initial curvature of the wing increases, initially the flutter velocity decreases but then increases, and finally a sudden jump occurs in the flutter velocity due to the change of the coupled modes contributing to flutter. Moreover, the flutter frequency also first decreases as the curvature of the wing increases, and then there is a sudden jump in the frequency, and from this point again the frequency decreases. Finally, results highlighting the importance of the initial curvature and the length of the curved segment on the stability velocity and frequency of the curved wing are presented.

Keywords: Curved wings, Aeroelastic instability, initial curvature, fully intrinsic equations, unsteady aerodynamics.

\footnotetext{
${ }^{1}$ Senior Lecturer, School of Computing and Engineering, University of Huddersfield.

${ }^{2}$ Professor, School of Mechanical Engineering, Shiraz University.

${ }^{3}$ Associate Professor, College of Engineering, Swansea University.

${ }^{4}$ Professor, College of Engineering, Swansea University.

${ }^{5}$ Professor, Department of Aerospace Engineering, Bristol University.
} 


\section{Introduction}

The aeroelasticity of aircraft wings is a topic of interest especially for flexible aircraft. The mutual interaction of structural dynamics and aerodynamic loads may result in limitations in the operational condition of the aircraft. For a safe aircraft, Airworthiness Regulations define that the flutter instability should stay well outside the flight envelope, and therefore it is very important to find the flutter boundaries of the aircraft for various flight conditions, weight conditions, etc. The aeroelastic stability of aircraft wings has been an active research topic since 1917 where one of the first studies that dealt with flutter analysis was presented by Bairstow and Fage [1] describing the investigation into the flutter instability that occurred in the horizontal tail of the twin-engined Handley Page O/400. Goland [2] studied the flutter of a uniform aircraft wing through integration of the governing differential equations. The effect of adding wing-tip weights on the flutter of the wing was studied by Goland and Luke [3]. The shape of the wing planform is one of the important factors that derives the performance characteristics of aircraft. Usually, the planform shape of the wing is a trade-off between different flight conditions and is not always the optimized shape for each flight condition. Therefore, the idea of changing the wing planform in flight to optimize the shape of the wing in each flight condition has been proposed $[4,5]$. Morphing wings enhance the performance of the wing by changing the shape of lifting surfaces using some form of mechanism [4, 5]; however, any change in the wing planform might affect the aeroelastic behaviour of the wing. Therefore, the aeroelastic stability of such wings should also be considered in a flight configuration.

Changing the sweep of the wing in flight was one of the earliest ways of changing planform in flight to reach higher cruise velocities. Lottati [6] showed that the sweep of the wing can influence the aeroelastic stability of a wing made of composite materials. Gern and Librescu [7] studied the aeroelastic stability of swept wings carrying external masses mounted under the wing. The aeroelastic instability of a swept wing subjected to the an engine was studied by Mazadi and Fazelzadeh [8]. They concluded that the engine thrust and mass and the wing sweep angle can affect the aeroelastic instability boundaries of the swept wing. Adding winglets to the tips of wings is a way of altering the aerodynamic loads which can result in lower loads on the wing but can change its aeroelastic behaviour compared to that of the clean wing. Goetz et al. [9] showed numerically and experimentally that when a wing has tip fins, the flutter velocity changes primarily due to the structural effects. Moreover, the effect of the winglet stiffness and mass on the aeroelastic stability of wings was studied by Dogget and Farmer [10] where it was shown that when a winglet is added to the wing, the flutter dynamic pressure reduces, and a larger reduction in flutter dynamic pressure was observed for heavier 
winglets. Peng and Jinglong [11] considered the aeroelasticity of wings with C-type wing tips and they concluded that when the winglet is added to a wing, the flutter velocity reduces by $10 \%$. Lv et al. [12] studied the effect of wingtips on the transonic aeroelasticity wings experimentally and showed that the shape of the winglet doesn't affect the flutter velocity significantly, whilst the weight of the winglet significantly decreases the flutter velocity. They also showed that the aerodynamic loads of the winglet have little impact on the aeroelasticity of the wing.

Changing the twist of the wing is another option that modifies the aerodynamic loads on the wing. Twist morphing was one of the popular concepts considered over recent decades, and several concepts have been proposed [4]. Twist morphing has been implemented to enhance roll control [13], to minimize the induced drag [14], to enhance the aerodynamic performance [15], or to reduce the aerodynamic drag [16]. Furthermore, it has been shown that the wing pre-twist shape and angle can affect the flutter velocity and frequency of the wings [17-19]. Depending on the twist shape and value, the flutter velocity can increase or decrease.

Recently, it has been proposed that curved wings can result in a reduction of drag and fuel burn [20]. Wings that are curved in the spanwise direction are inspired from nature, and a drooped wing shape could decrease the wing drag by up to $6 \%$, and an inflected wing may result in a drag reduction of $4 \%$ [19]. Although manufacturing aircraft wings with an initial curvature can have some benefits on the aerodynamics, it could also change the structural dynamics of the wing significantly. The effect of initial in-plane or out-of-plane curvature on the dynamics of curved beams has been extensively addressed by many researchers [21]. Hodges [22] showed that initially curved isotropic beams introduce stretch-bending coupling in the beam. Chang and Hodges [23] determined the vibration characteristics of curved beams by using fully intrinsic equations and observed a transition between dominant modes for certain values of initial curvature. Therefore, the curvature of the wing not only influences the aerodynamics of the wing, but also affects the dynamics of the wing and hence the aeroelastic behaviour of the wing.

In this study, the aeroelasticity of aircraft wings with initial curvature is considered, and the change in the flutter velocity and frequency with respect to the out-of-plane curvature is determined. The aeroelastic problem is formulated by combining the geometric exact intrinsic beam formulations [24] with the unsteady Peters' aerodynamic theory [25]. Finally, the effect of initial curvature on the dynamics, flutter velocity, and flutter frequency of a typical wing is discussed. 


\section{Problem Statement}

An aircraft wing, modelled as a cantilever beam, with initial curvature, as shown in Figure 1, is considered. The reference coordinate system is fixed at the root of the wing in which $x$ axis lies in the span direction and towards the tip, $y$ is towards the chord of the wing and $z$ is upward in the thickness direction. It is assumed that the wing has a constant curvature over the span of the wing. Two cases are considered here to investigate the effect of curvature on the aeroelastic instability of the wing. In the first case, it is considered that the span length or the perimeter of the wing is constant, and when it is curved the projected area of the wing decreases. In the second case, the projected area of the wing is considered to be constant, and therefore the span length of the wing is not fixed. These two cases are considered to determine whether either approach enhances the aeroelastic behaviour of the wing. The curvature radius is denoted here as $R_{r}$, and the arc angle of the curved beam is defined as

$$
\alpha=L k_{2}
$$

where $L$ and $k_{2}$ are the span length and the initial curvature of the beam, respectively as shown in Figure 2. In this study, it is assumed that all the structural properties of the wing remain intact when an additional curvature is added to the wing.

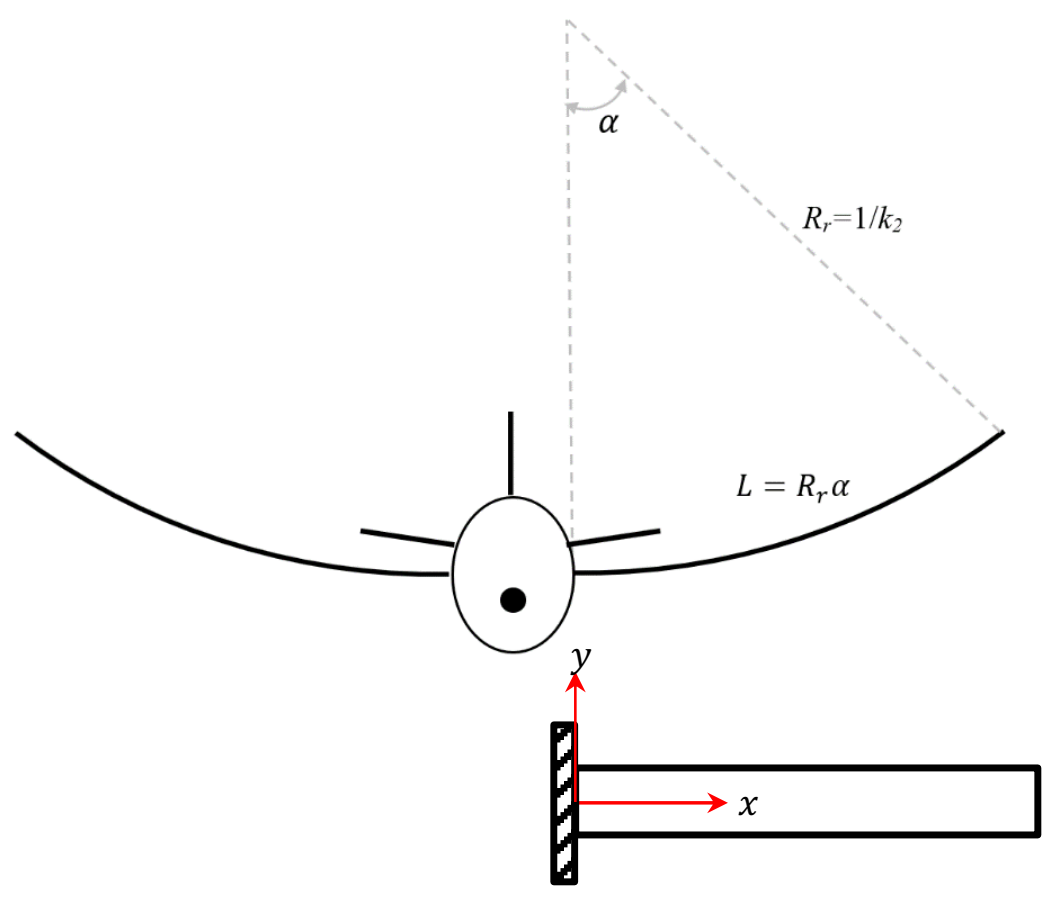


Figure 1: The schematic of the curved wing with constant initial curvature.

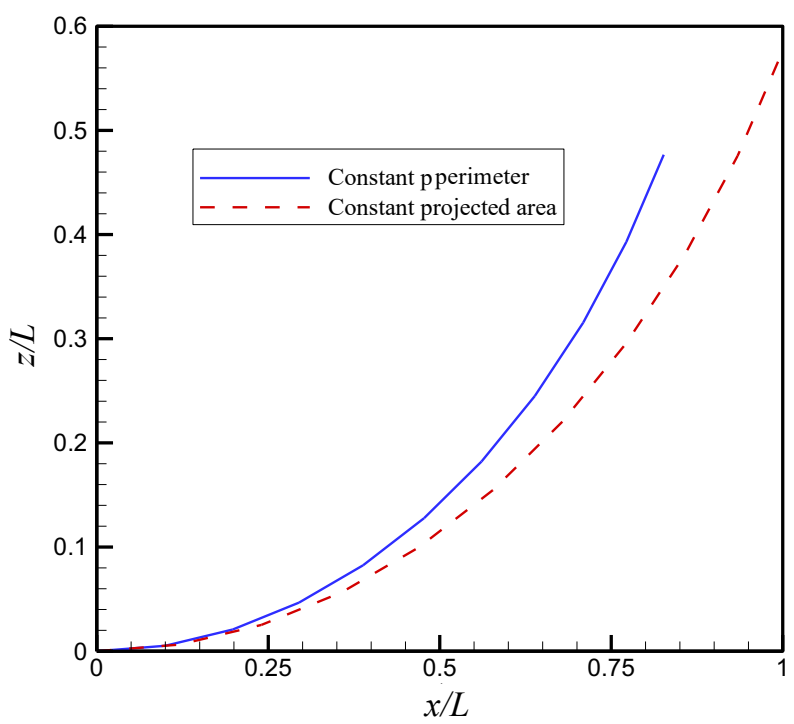

Figure 2: The curved shapes of the wing for constant perimeter and constant projected area cases for $k_{2}=60 \mathrm{deg} / \mathrm{m}$.

\section{Equations of Motion}

The curved wing of the aircraft is modelled by using the geometrically exact intrinsic beam formulation [24]. This exact beam formulation has been implemented successfully recently for a various of different aerospace structure applications [26-35] such that

$$
\begin{aligned}
& \partial F_{1} / \partial x+K_{2} F_{3}-K_{3} F_{2}+f_{1_{\text {aero }}}=\partial P_{1} / \partial t+\Omega_{2} P_{3}-\Omega_{3} P_{2} \\
& \partial F_{2} / \partial x+K_{3} F_{1}-K_{1} F_{3}+f_{2_{\text {aero }}}=\partial P_{2} / \partial t+\Omega_{3} P_{1}-\Omega_{1} P_{3} \\
& \partial F_{3} / \partial x+K_{1} F_{2}-K_{3} F_{1}+f_{3_{\text {aero }}}=\partial P_{3} / \partial t+\Omega_{1} P_{2}-\Omega_{2} P_{1} \\
& \partial M_{1} / \partial x+K_{2} M_{3}-K_{3} M_{2}+2 \gamma_{12} F_{3}-2 \gamma_{13} F_{2}+m_{1_{\text {aero }}}=\partial H_{1} / \partial t+\Omega_{2} H_{3}-\Omega_{3} H_{2}+V_{2} P_{3}-V_{3} P_{2} \\
& \partial M_{2} / \partial x+K_{3} M_{1}-K_{1} M_{3}+2 \gamma_{13} F_{1}-\left(1+\gamma_{11}\right) F_{3}+m_{2_{\text {aero }}}=\partial H_{2} / \partial t+\Omega_{3} H_{1}-\Omega_{1} H_{3}+V_{3} P_{1}-V_{1} P_{3} \\
& \partial M_{3} / \partial x+K_{1} M_{2}-K_{2} M_{1}+\left(1+\gamma_{11}\right) F_{2}-2 \gamma_{12} F_{1}+m_{3 \text { aero }}=\partial H_{3} / \partial t+\Omega_{1} H_{2}-\Omega_{2} H_{1}+V_{1} P_{2}-V_{2} P_{1} \\
& \partial V_{1} / \partial x+K_{2} V_{3}-K_{3} V_{2}+2 \gamma_{12} \Omega_{3}-2 \gamma_{13} \Omega_{2}=\partial \gamma_{11} / \partial t \\
& \partial V_{2} / \partial x+K_{3} V_{1}-K_{1} V_{3}-\left(1+\gamma_{11}\right) \Omega_{3}+2 \gamma_{13} \Omega_{1}=2 \partial \gamma_{12} / \partial t \\
& \partial V_{3} / \partial x+K_{1} V_{2}-K_{2} V_{1}+\left(1+\gamma_{11}\right) \Omega_{2}-2 \gamma_{12} \Omega_{1}=2 \partial \gamma_{13} / \partial t \\
& \partial \Omega_{1} / \partial x+K_{2} \Omega_{3}-K_{3} \Omega_{2}=\partial \kappa_{1} / \partial t
\end{aligned}
$$


$\partial \Omega_{2} / \partial x+K_{3} \Omega_{1}-K_{1} \Omega_{3}=\partial \kappa_{2} / \partial t$

$\partial \Omega_{3} / \partial x+K_{1} \Omega_{2}-K_{2} \Omega_{1}=\partial \kappa_{3} / \partial t$

where $F_{i}$ and $M_{i}$ for $i=1,2,3$ are the sectional internal forces and moments, $V_{i}$ and $\Omega_{i}$ are the linear and angular velocities, $P_{i}$ and $H_{i}$ are vectors containing the sectional linear and angular momenta, respectively. $\gamma_{1 i}$ and $\kappa_{1 i}$ are the generalized strains of the beam. The vector of the final curvature and the twist of the deformed beam is denoted by $K_{i}$ which can be described by

$$
K_{i}=\kappa_{i}+k_{i}
$$

where $k_{i}$ denotes the initial curvature and twist values of the beam. In this study, the wing is assumed to have an initial out-of-plane curvature, $k_{2}$, which then changes the final curvature $K_{2}$ value; this adds an additional coupling between the equations in Eq. (1).

All variables that appear in Eq. (1) are described in the deformed coordinate reference system except the initial curvature and twist which are based on the undeformed reference frame. In this study, it is assumed that the wing has an initial curvature and therefore $k_{i}$ is not zero. The moment and force vectors are related to the generalized strain through the stiffness matrix as

$$
\left[\begin{array}{l}
F_{1} \\
F_{2} \\
F_{3} \\
M_{1} \\
M_{2} \\
M_{3}
\end{array}\right]=\left[\begin{array}{llllll}
S_{11} & S_{12} & S_{13} & S_{14} & S_{15} & S_{16} \\
S_{12} & S_{22} & S_{23} & S_{24} & S_{25} & S_{26} \\
S_{13} & S_{23} & S_{33} & S_{34} & S_{35} & S_{36} \\
S_{14} & S_{24} & S_{34} & S_{44} & S_{45} & S_{46} \\
S_{15} & S_{25} & S_{35} & S_{45} & S_{55} & S_{56} \\
S_{16} & S_{26} & S_{36} & S_{46} & S_{56} & S_{66}
\end{array}\right]\left[\begin{array}{c}
\gamma_{11} \\
2 \gamma_{12} \\
2 \gamma_{13} \\
\kappa_{1} \\
\kappa_{2} \\
\kappa_{3}
\end{array}\right]
$$

where $S_{i j}$ for $i, j=1, . ., 6$ are the cross-sectional stiffness values of the beam. Moreover, the linear and angular momenta can be calculated as 


$$
\left[\begin{array}{l}
P_{1} \\
P_{2} \\
P_{3} \\
H_{1} \\
H_{2} \\
H_{3}
\end{array}\right]=\left[\begin{array}{cccccc}
\mu & 0 & 0 & 0 & \mu x_{3} & -\mu x_{2} \\
0 & \mu & 0 & -\mu x_{3} & 0 & 0 \\
0 & 0 & \mu & \mu x_{2} & 0 & 0 \\
0 & -\mu x_{3} & \mu x_{2} & i_{2}+i_{3} & 0 & 0 \\
\mu x_{3} & 0 & 0 & 0 & i_{2} & i_{23} \\
-\mu x_{2} & 0 & 0 & 0 & i_{23} & i_{3}
\end{array}\right]\left[\begin{array}{l}
V_{1} \\
V_{2} \\
V_{3} \\
\Omega_{1} \\
\Omega_{2} \\
\Omega_{3}
\end{array}\right]
$$

where $\mu$ is the mass per unit length, $\mathbf{x}=\left[x_{1}, x_{2}, x_{3}\right]^{\mathrm{T}}$ is a vector storing the offsets between the mass centroid and the reference axis, and $\mathbf{i}=\left[i_{1}, i_{2}, i_{3}\right]^{\mathrm{T}}$ is the vector containing the mass moments of inertia of the beam.

The wing is subjected to incompressible unsteady aerodynamic loads simulated here by implementing the intrinsic representation of Peters' formulation ([25]) as follows:

$$
\begin{array}{ll}
f_{i_{\text {aero }}}=C_{a} F_{i_{a}} & \text { for } i=1,2,3 \\
m_{i_{\text {aero }}}=C_{a} M_{i_{a}}+C_{a} \tilde{y}_{a c} F_{i_{a}} & \text { for } i=1,2,3
\end{array}
$$

where $C_{a}$ transforms the variables from the aerodynamic reference frame system to the beam reference frame system, the superscript $(\widetilde{\sim})$ is the tilde operator, which transforms the vector $\mathbf{A}$ to its corresponding matrix as

$$
\boldsymbol{A}=\left[a_{1}, a_{2}, a_{3}\right]^{T}, \quad \widetilde{\boldsymbol{A}}=\left[\begin{array}{ccc}
0 & -a_{3} & a_{2} \\
a_{3} & 0 & -a_{1} \\
-a_{2} & a_{1} & 0
\end{array}\right]
$$

Rivera [36] experimentally considered the effect of wing curvature on the flutter speed of two wing models, and showed that the variation of flutter speed with respect to the wing curvature is primarily due to the structural properties. Furthermore, Smith et al. [37] showed that using linear aerodynamic models give conservative predictions of flutter speeds. Therefore, in this study, the effect of wakes that are generated due to the wing curvature has not been considered. However, this should be clearly investigated, especially for highly curved wings, in future studies. Moreover, $F_{i_{a}}, M_{i_{a}}$ for $i=1,2,3$ ( 1 for spanwise, 2 for chordwise, 3 for thickness wise) are the aerodynamic forces and moments in the aerodynamic reference frame which are

$$
F_{1 a}=0
$$




$$
\begin{aligned}
& F_{2_{a}}=\rho b\left(-C_{l_{0}} V_{T} V_{a_{3}}+C_{l_{\alpha}}\left(V_{a_{3}}+\lambda_{0}\right)^{2}-C_{d_{0}} V_{T} V_{a_{2}}\right) \\
& F_{3_{a}}=\rho b\left(C_{l_{0}} V_{T} V_{a_{2}}-C_{l_{\alpha}} \dot{V}_{a_{3}} b / 2-C_{l_{\alpha}} V_{a_{2}}\left(V_{a_{3}}+\lambda_{0}-\Omega_{a_{1}} b / 2\right)-C_{d_{0}} V_{T} V_{a_{3}}\right) \\
& M_{1_{a}}=2 \rho b^{2}\left(C_{m_{0}} V_{T}^{2}-C_{m_{\alpha}} V_{T} V_{a_{3}}-C_{l_{\alpha}} V_{a_{2}} \Omega_{a_{1}} b / 8-C_{l_{\alpha}}\left(b^{2} / 32 \dot{\Omega}_{a_{1}}-b / 8 \dot{V}_{a_{3}}\right)\right) \\
& M_{2_{a}}=M_{3 a}=0
\end{aligned}
$$

where $C_{l_{0}}, C_{l_{\alpha}}, C_{d_{0}}, C_{m_{0}}$, and $C_{m_{\alpha}}$ are the aerodynamic coefficients of the wing airfoil. The subscript ( $a$ ) refers to the aerodynamic reference frame system, and $V_{T}$ is the resultant aerodynamic velocity that can be written as

$$
V_{T}=\sqrt{V_{a_{2}}^{2}+V_{a_{3}}^{2}}
$$

Furthermore, $\lambda_{0}$ is the inflow value which can be determined using the following equations [25]

$$
\begin{aligned}
& {[A]\{\dot{\lambda}\}+\left(\frac{V_{T}^{n}}{B^{n}}\right)\{\lambda\}=\left(-\dot{V}_{a_{3}}+\frac{b}{2} \dot{\Omega}_{a_{3}}\right)\{C\}} \\
& \lambda_{0}=\frac{1}{2}\{B\}^{T}\{\lambda\}
\end{aligned}
$$

where $\{\lambda\}$ is a vector storing the inflow states and $[A],\{B\}$, and $\{C\}$ are constant matrices/vectors defined as

$$
\begin{aligned}
& {[A]=[D]+\{d\}\{B\}^{T}+\{C\}\{d\}^{T}+\frac{1}{2}\{C\}\{B\}^{T}} \\
& B_{n}= \begin{cases}(-1)^{n-1} \frac{(N+n-1) !}{(N-n-1) !} \frac{1}{(n !)^{2}} & n \neq N \\
(-1)^{n-1} & n=N\end{cases} \\
& C_{n}=\frac{2}{n} \\
& d_{n}= \begin{cases}\frac{1}{2} & (n \neq 1) \\
0 & (n=1)\end{cases}
\end{aligned}
$$




$$
D_{n m}=\left\{\begin{array}{cc}
\frac{1}{2 n} & (n=m+1) \\
-\frac{1}{2 n} & (n=m-1) \\
0 & (n \neq m \pm 1)
\end{array}\right.
$$

The wing is modelled by a cantilever beam, and the following boundary conditions on force, moment, velocity, and angular velocity are applied to the equations of motion such that

$$
\left[\begin{array}{l}
F_{1}(L, t) \\
F_{2}(L, t) \\
F_{3}(L, t)
\end{array}\right]=\left[\begin{array}{l}
0 \\
0 \\
0
\end{array}\right],\left[\begin{array}{l}
M_{1}(L, t) \\
M_{2}(L, t) \\
M_{3}(L, t)
\end{array}\right]=\left[\begin{array}{l}
0 \\
0 \\
0
\end{array}\right],\left[\begin{array}{l}
V_{1}(0, t) \\
V_{2}(0, t) \\
V_{3}(0, t)
\end{array}\right]=\left[\begin{array}{c}
0 \\
U_{\infty} \\
0
\end{array}\right],\left[\begin{array}{l}
\Omega_{1}(0, t) \\
\Omega_{2}(0, t) \\
\Omega_{3}(0, t)
\end{array}\right]=\left[\begin{array}{l}
0 \\
0 \\
0
\end{array}\right]
$$

where $U_{\infty}$ is the free steam velocity.

The governing aeroelastic equations of the wing are discretized by using a space-time discretization scheme [24]. Selecting 16 elements was sufficient to ensure the results had converged. To study the aeroelastic stability, first the nonlinear steady state condition of the system is determined by setting all time derivatives to zero and fixing all time dependent variables in the aeroelastic equations. Then, the nonlinear differential equations are linearized about the steady state condition. Finally, the eigenvalues of the linearized system are determined to check the stability of the system about the steady-state condition.

\section{Numerical Results}

To validate the developed code, first the nondimensional frequencies of a curved beam are calculated and compared with those reported by [38], and presented in Table 1 . In this case, the curvature angle is $\alpha=180^{\circ}$, and the results show a good agreement.

In the next step, the flutter velocity of an aircraft wing is determined and compared with [39]. In [39] the exact mixed variational formulation was combined with Peter's unsteady aerodynamics model and the modified ONERA dynamic stall model, while in this study the exact fully intrinsic equations have been used. The wing is similar to the clean Goland wing without tip mass, and the wing properties are presented in Table 2 . The flutter velocity and flutter 
frequency of this wing are determined and compared with the results presented by [39] in Table 3. It is clear that the aeroelastic results by the present method are in very good agreement with those of Patil et al. [39]. In what follows, the effect of the initial curvature on the flutter velocity and frequency of the Goland wing is determined.

Table 1: Comparison of the nondimensional frequencies $\left(\phi=\sqrt{\mu \omega^{2} L^{4} / E I}\right)$ of a curved cantilever beam

\begin{tabular}{ccc}
\hline \hline Mode No. & Present & Rosa and Franciosi [38] \\
\hline 1 & 0.43541 & 0.435 \\
2 & 1.3781 & 1.375 \\
3 & 4.7311 & 4.71 \\
4 & 10.604 & 10.52 \\
\hline \hline
\end{tabular}

Table 2: Clean Goland wing structural and aerodynamic properties

\begin{tabular}{lll}
\hline \hline Parameter & Definition & Value \\
\hline$L$ & Wing semi-span & $6.1 \mathrm{~m}$ \\
$c$ & Wing chord & $1.83 \mathrm{~m}$ \\
$G J$ & Torsional Stiffness & $0.99 \times 10^{6} \mathrm{~N} \cdot \mathrm{m}^{2}$ \\
$E I_{2}$ & Bending Stiffness & $9.77 \times 10^{6} \mathrm{~N} \cdot \mathrm{m}^{2}$ \\
$\mu$ & Mass per unit length & $35.7 \mathrm{~kg} / \mathrm{m}$ \\
$i_{3}$ & Mass moment of inertia & $8.64 \mathrm{~kg} . \mathrm{m}$ \\
$x_{e . a .}$ & Elastic axis offset from & $33 \%$ chord \\
& L.E. & \\
$x_{c . g .}$ & Centre of gravity offset & $43 \%$ chord \\
& from L.E. & \\
$y_{a c}$ & Aerodynamic center & $25 \%$ chord \\
& offset from L.E. & \\
$C_{l_{\alpha}}$ & Lift curve slope & $2 \pi$
\end{tabular}


Table 3: Comparison of the flutter velocity and flutter frequency of the Goland wing

\begin{tabular}{lll}
\hline \hline & Present & Patil et al. [39] \\
\hline Flutter velocity $(\mathrm{m} / \mathrm{s})$ & 135.6 & 136 \\
Flutter frequency (rad/s) & 70.23 & 70.2 \\
\hline \hline
\end{tabular}

When the wing has an initial curvature, the aeroelastic properties of the wing change, and therefore it is important to check the impact on the onset of instability. This paper emphasizes the changes that the wing curvature makes to the structural dynamics of the wing. As mentioned earlier, the wing has an initial out-of-plane curvature, $k_{2}$, which is constant along the wing span. The deformed shape of the wing for various curvature angles for the cases of constant perimeter and constant projected area are shown in Figures 3 and 4 respectively. In the second case (constant projected area), the length of the wing is modified for each curvature value to create a constant projected area equal to that of the baseline Goland wing.

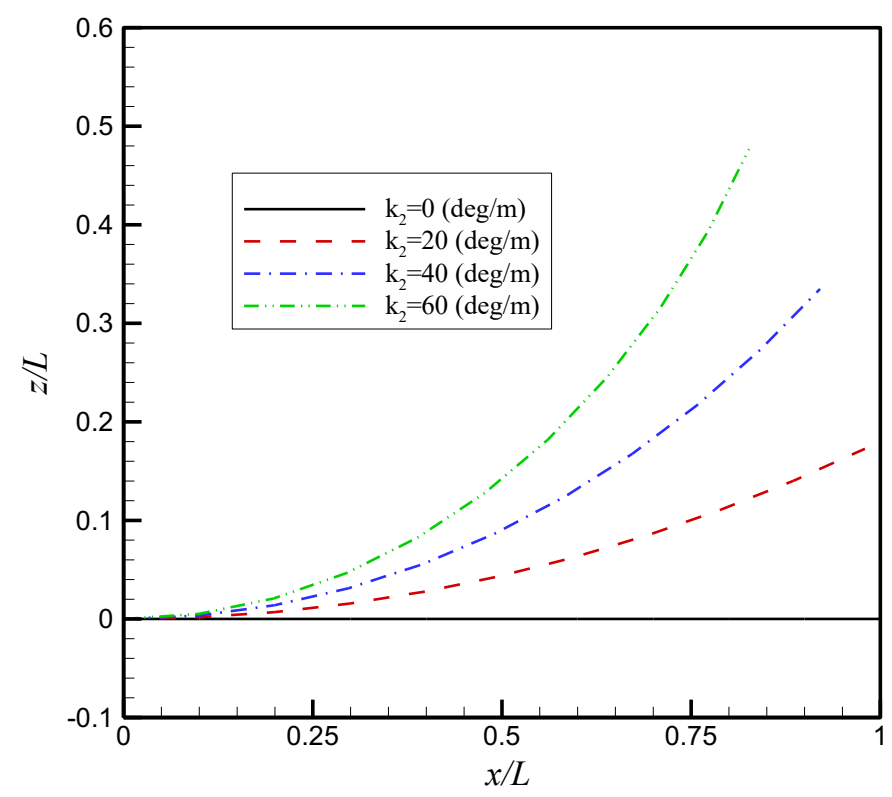

Figure 3: The deformed shape of the wing for the constant perimeter case. 


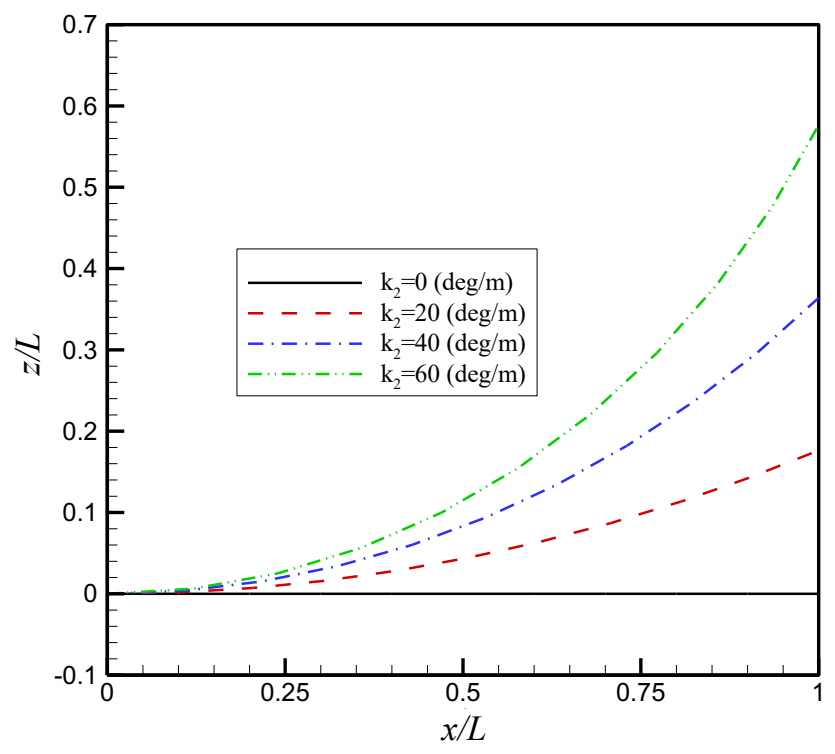

Figure 4: The deformed shape of the wing for the constant projected area case.

First, the effect of the initial curvature on the first three natural frequencies of the wing is determined and shown in Figure 5. The offset between the centre of gravity and reference axis of the wing means that all of the modes are coupled, and they are combinations of out-of-plane bending and torsion ([40]). By increasing the initial curvature of the wing, the two first modes approach each other until a certain value of curvature, and after that they veer away from each other. In this case, the veering occurs when the initial curvature is about $k_{2}=55 \mathrm{deg} / \mathrm{m}$. Furthermore, Figures 6 and 7 show the torsion $\left(\Phi_{M_{1}}\right)$ and flap $\left(\Phi_{M_{2}}\right)$ eigenvectors of the modes which have been normalised so that the 2norm of each mode is equal to 1 . It is clear that the wing curvature affects the mode shapes and the coupling that exists between them. This clearly shows that the wing curvature affects the structural dynamics, especially the higher modes, and hence changes the aeroelasticity characteristics of the wing. Therefore, in what follows the aeroelastic stability of the curved wings is investigated. 


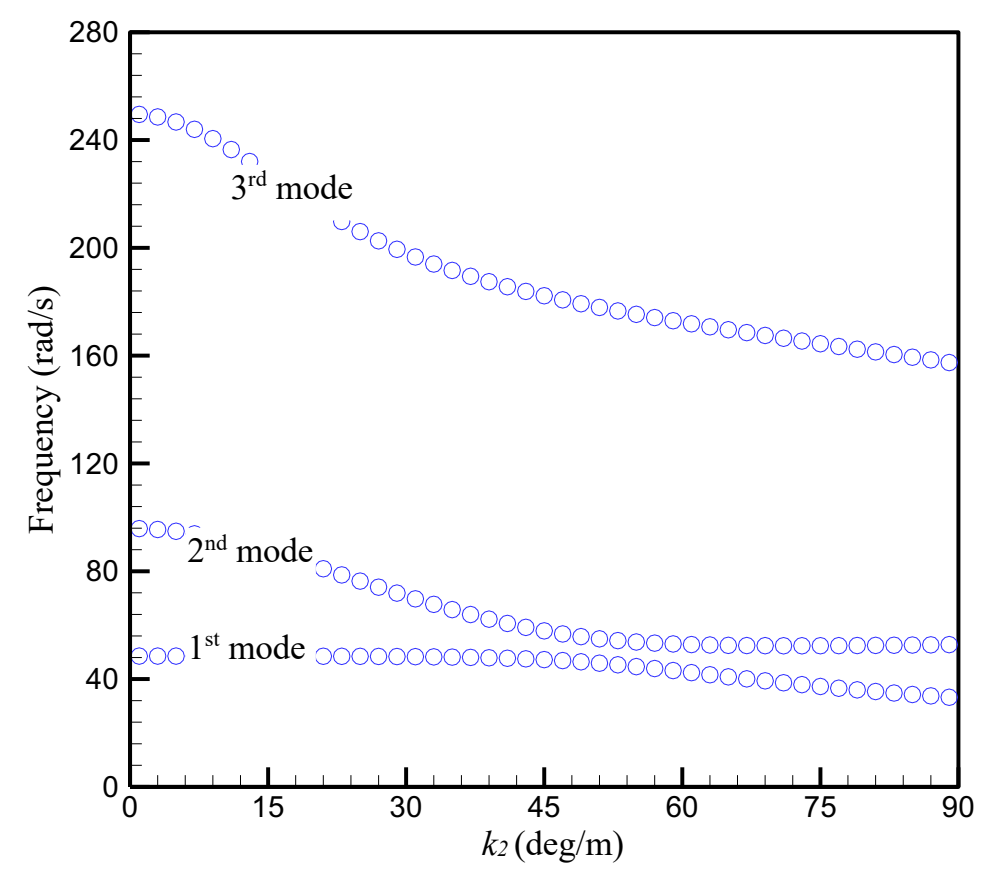

Figure 5: The natural frequencies of the wing for different values of out-of-plane curvature for the constant perimeter case.
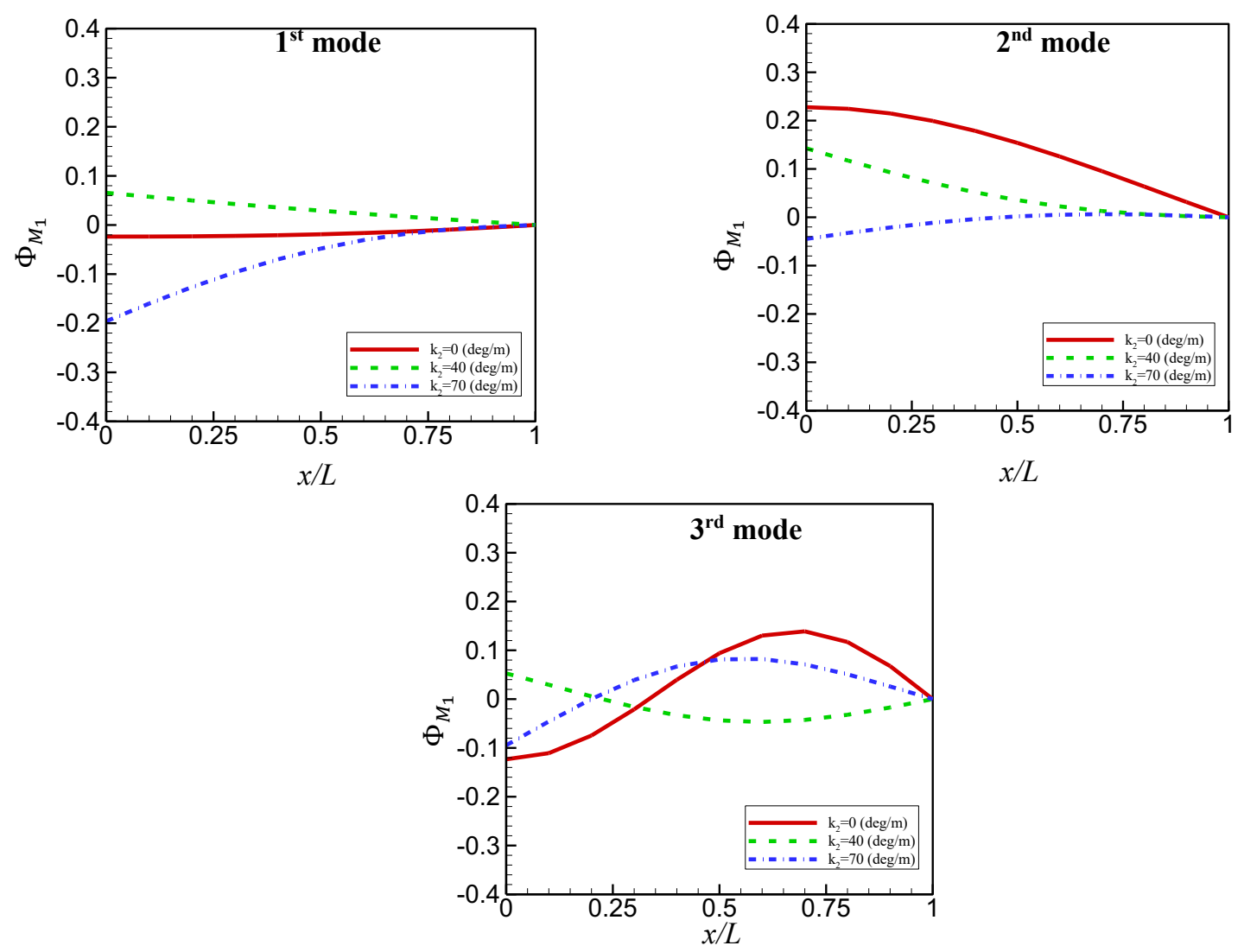

Figure 6: The effect of wing curvature on the torsion component of the modes. 

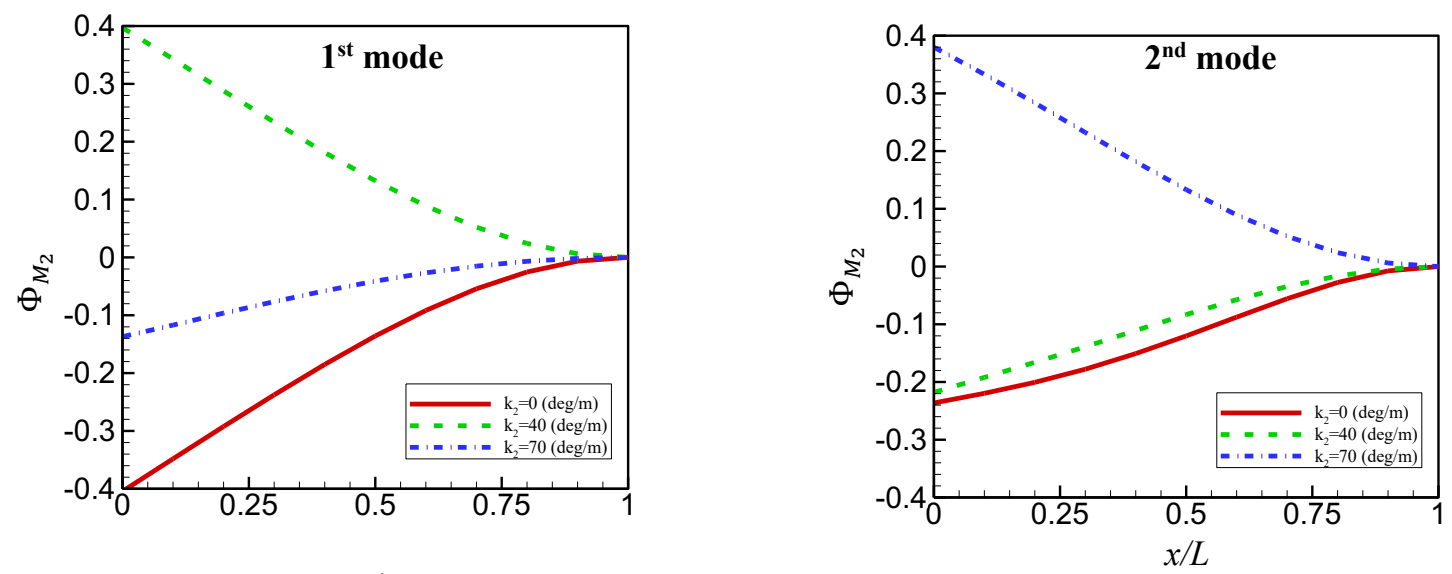

$x / L$

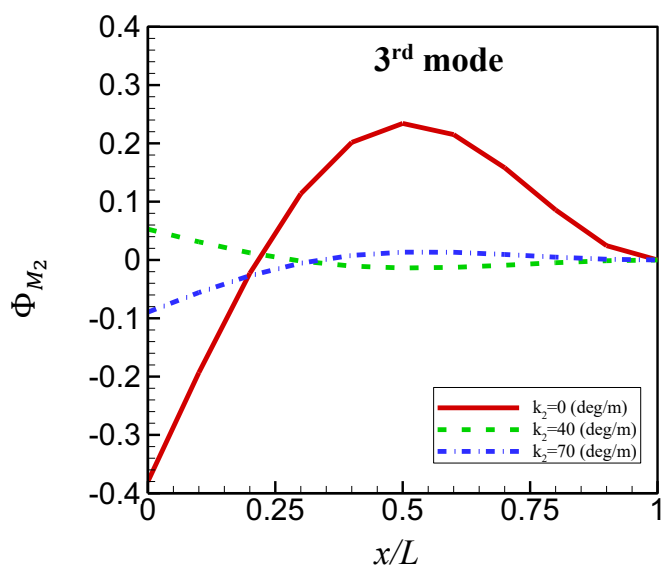

Figure 7: The effect of wing curvature on the flap component of the modes.

The effect of the initial curvature on the flutter velocity and flutter frequency of the wing for the case of constant perimeter is determined. Figure 8 shows the change in flutter velocity of the wing for various initial out-of-plane curvature angles. Note that from here on, all the results are nondimensionalised with respect to the baseline Goland wing which has the properties presented in Table 2 (subscript ${ }_{s}$ ). When the wing has an initial curvature, at first the flutter velocity decreases until about $k_{2}=45 \mathrm{deg} / \mathrm{m}$, which is mainly due to the initial coalescence of the first and second modes, as shown in Figure 5. Then, the flutter velocity increases gradually until about $k_{2}=67 \mathrm{deg} / \mathrm{m}$ where the interaction between the first and second modes is still the main cause of flutter, but these modes then veer away from each other. A sudden increase is then observed in flutter velocity which is mainly due to the flutter mechanism changing and, after this point, the flutter velocity decreases. Furthermore, as shown in Figure 9, the flutter frequency of the wing also decreases gradually until $k_{2}=67 \mathrm{deg} / \mathrm{m}$ where there is a jump in the flutter frequency, and then 
decreases again. The main reason for this sudden jump in the flutter velocity and flutter frequency is the change in the flutter modes as described below.

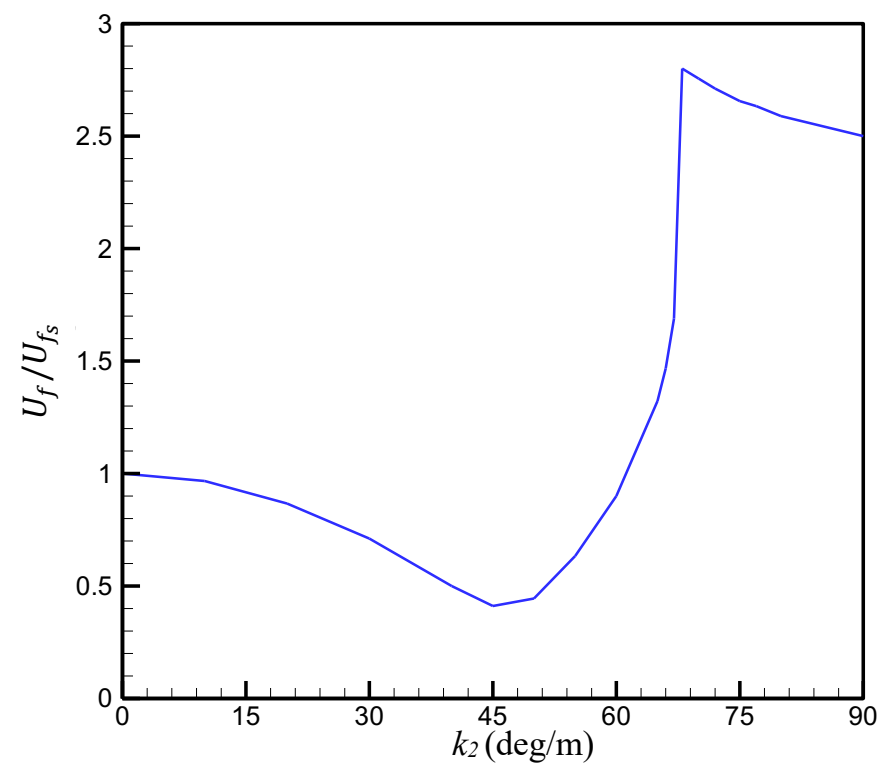

Figure 8: Flutter velocity versus out-of-plane curvature for the constant perimeter case.

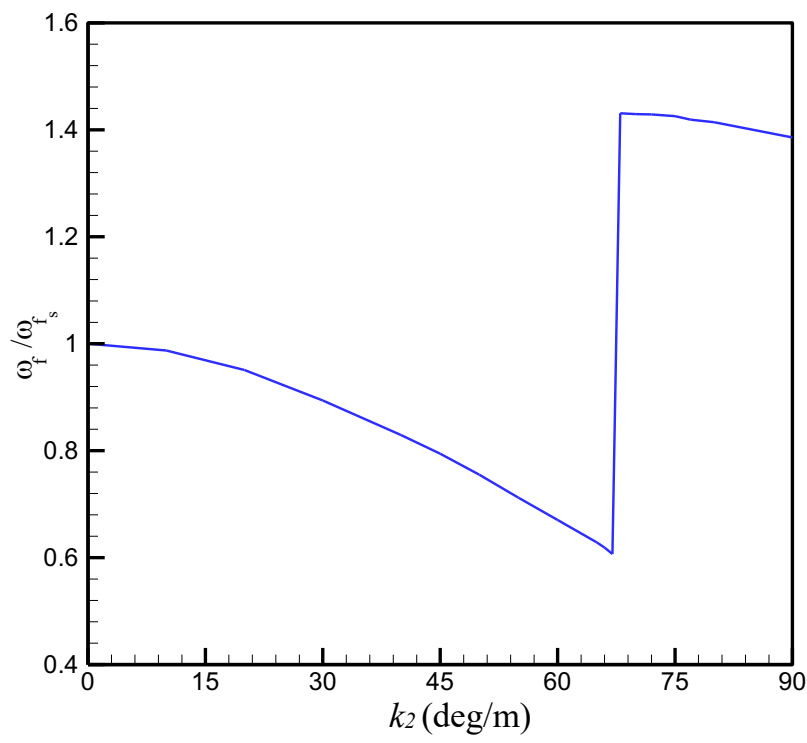

Figure 9: Flutter frequency versus out-of-plane curvature for the constant perimeter case.

When the initial curvature is smaller than $k_{2}<67 \mathrm{deg} / \mathrm{m}$, as shown in Figure 10, the flutter is the result of the coupling between the first and second modes. Also, it must be noted that in this region, by increasing the aircraft 
velocity, initially the first and second modes are coupled together, but after a certain value above the flutter velocity, the first and third modes are coupled together. Figure 11 also shows the change of damping ratio of the wing with respect to the flight velocity for an initial curvature of $k_{2}=60 \mathrm{deg} / \mathrm{m}$. It is noted that a change in the sign of damping ratio from positive to negative results to instability. It is clear that the initial unstable mode (second mode) becomes more stable as the velocity increases.

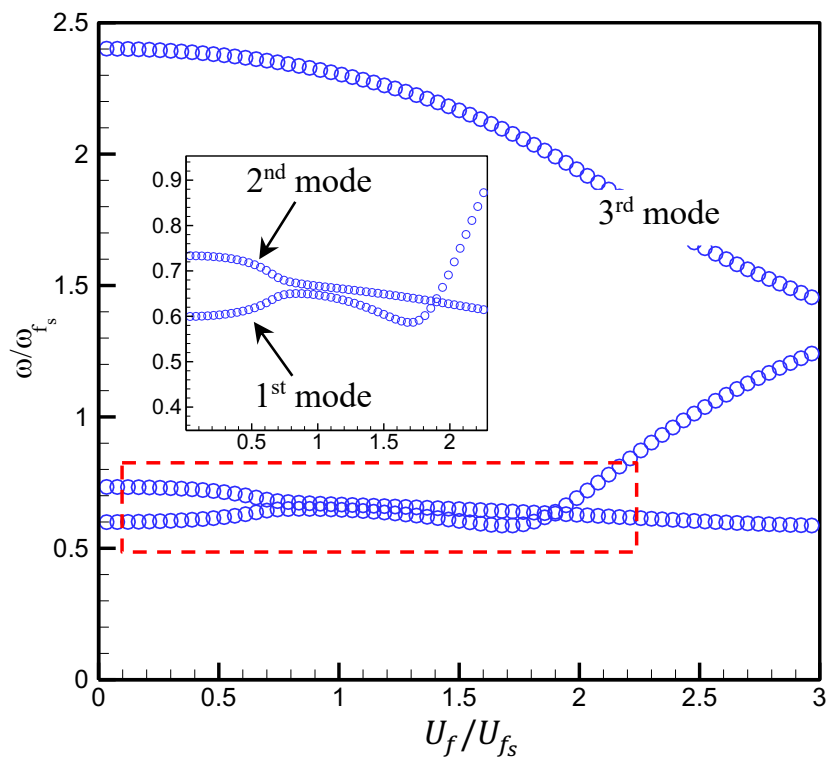

Figure 10: Aeroelastic frequencies versus velocity for $k_{2}=60 \mathrm{deg} / \mathrm{m}$,

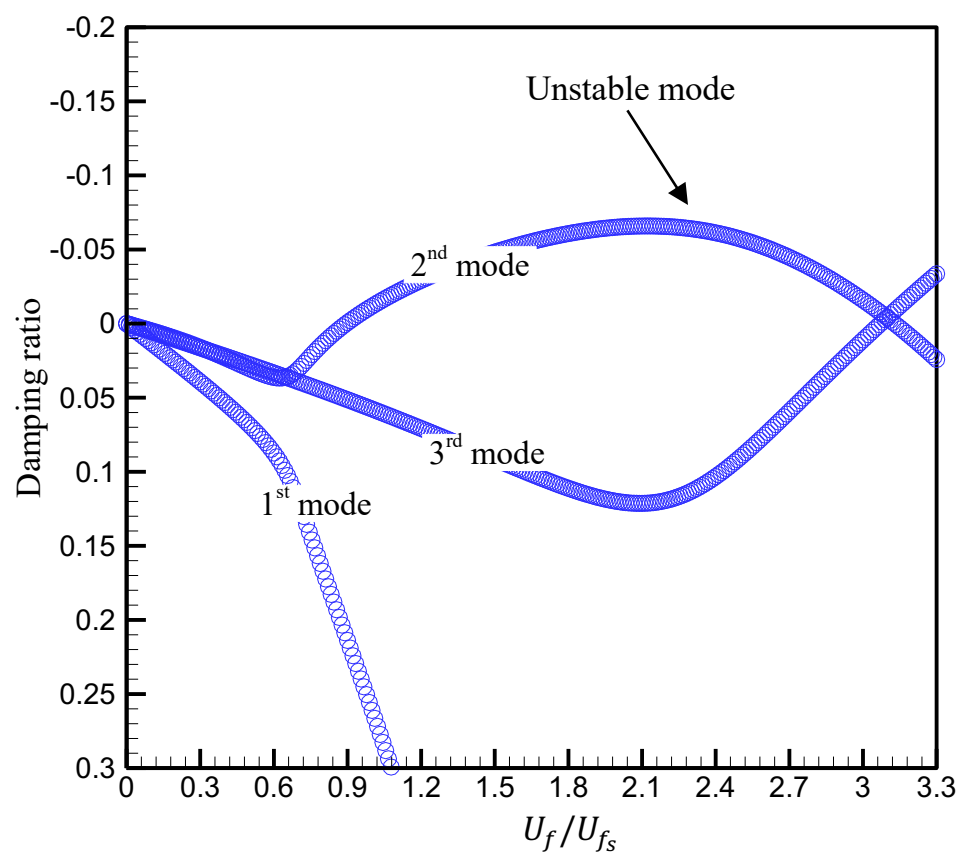


Figure 11: Aeroelastic damping ratio versus velocity for $k_{2}=60 \mathrm{deg} / \mathrm{m}$,

Moreover, for the domain of $k_{2} \geq 67 \mathrm{deg} / \mathrm{m}$, as shown in Figures 12, initially the first two modes approach together but then veer away from each other. Then, the first and third modes are coupled together which results in a higher flutter velocity. This clarifies the reason for the sudden jump shown in the flutter velocity and flutter frequency. To highlight this more, the evolution of the damping ratio of the wing when the initial curvature is $k_{2}=75 \mathrm{deg} / \mathrm{m}$ was determined and is shown in Figure 13. Note that the initially unstable mode in Figure 9 (second mode) does not become unstable here and hence the stability velocity increases.

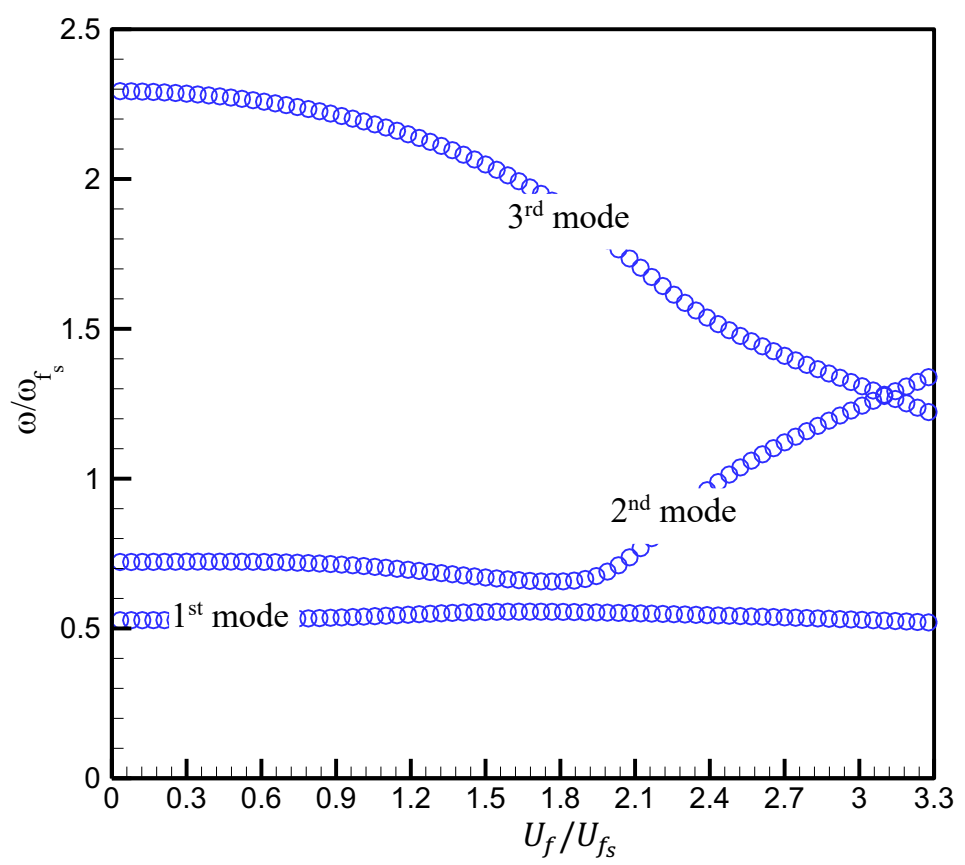

Figure 12: Aeroelastic frequencies versus velocity for $k_{2}=75 \mathrm{deg} / \mathrm{m}$. 


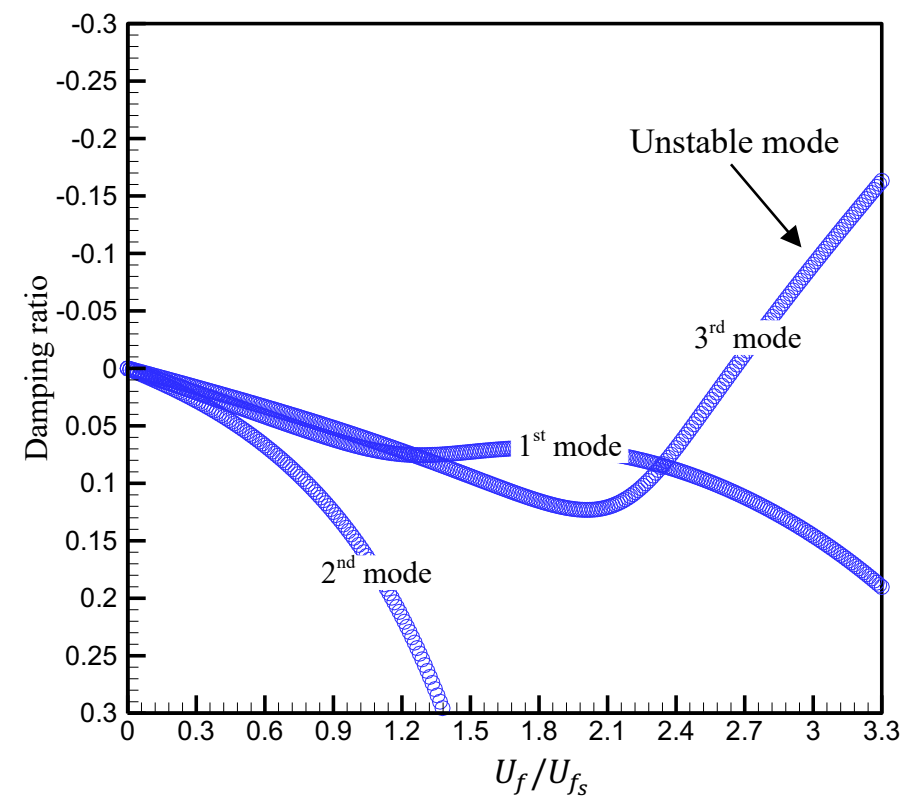

Figure 13: Aeroelastic damping ratio versus velocity for $k_{2}=75 \mathrm{deg} / \mathrm{m}$,

Next the flutter velocity and frequency of the second case (constant projected area) is determined and compared with those obtained for the constant perimeter case and shown in Figures 14 and 15. For lower values of initial curvature, there is no significant difference between the flutter velocity of these two cases, as shown in Figure 14, but for higher values of curvature angles, the difference tends to get larger. This pattern is also observed in Figure 15 for the flutter frequency. These findings highlight that the constant perimeter case tends to extend the stability region unlike the constant projected area case. Thus, from here on, the focus of the paper will be on the case of constant perimeter as it shows better aeroelastic behaviour and is arguable more realistic for the wing design process. However, this should be investigated more as there are other parameters such as the aerodynamics or morphing behaviour of the wing that might affect the aeroelasticity of these cases. 


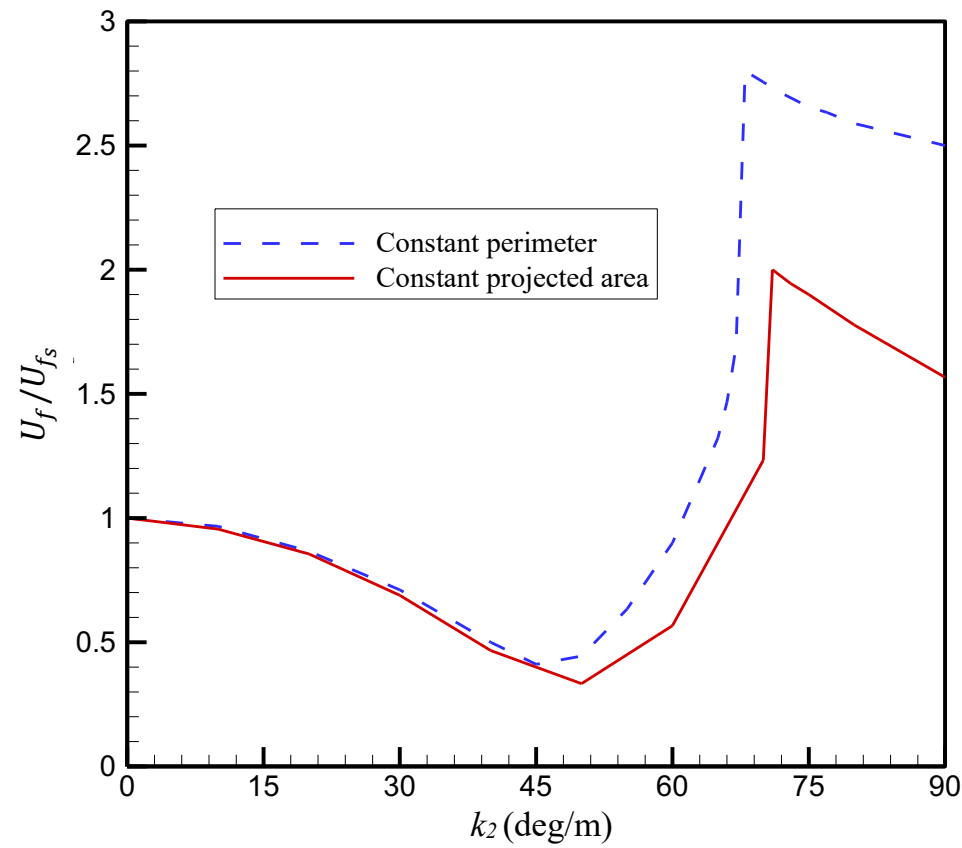

Figure 14: Flutter velocity for the constant perimeter case versus constant projected area for various initial curvatures,

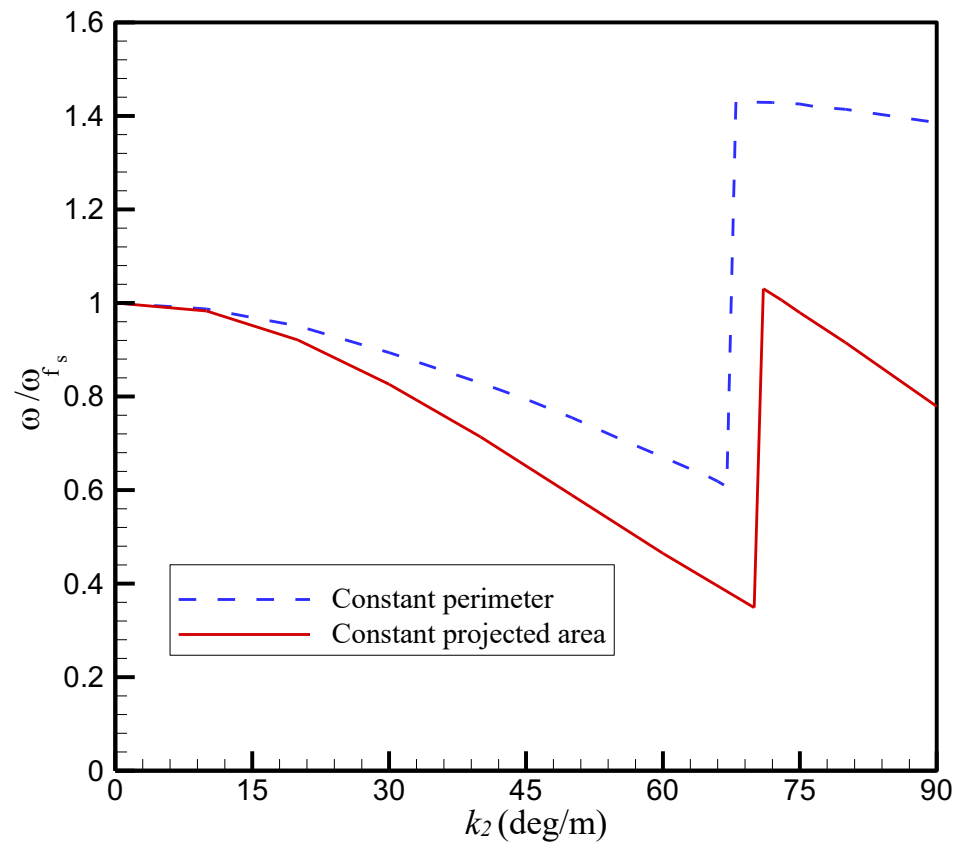

Figure 15: Flutter frequency for the constant perimeter case versus constant projected area for various initial curvatures. 
Figures 16 and 17 show the variation of flutter velocity and flutter frequency of the wing with respect to the initial curvature for different stiffness ratios $\left(\lambda=E I_{2} / G J\right)$. The stiffness ratio significantly affects the flutter velocity of the wing, but the trend of the change is different for various initial curvature angles. When the stiffness ratio decreases, the point at which the flutter velocity trend changes moves toward higher values of the curvature angle. Moreover, three regions are observed in Figure 16 where the stiffness ratio works differently. In the first and third regions the flutter velocity decreases by increasing the initial curvature, and when $\lambda$ decreases, the flutter velocity increases. But the situation is completely different in the middle region where the flutter velocity increases by increasing the curvature angle. In this region, when the stiffness ratio increases, the flutter velocity also increases. This result highlights the importance of the combination of the stiffness ratio and initial curvature on the flutter velocity. Moreover, the stiffness ratio also affects the flutter frequency as shown in Figure 17. For all initial curvature values, when the stiffness ratio increases, the flutter frequency also increases, but the rate of increase is not constant.

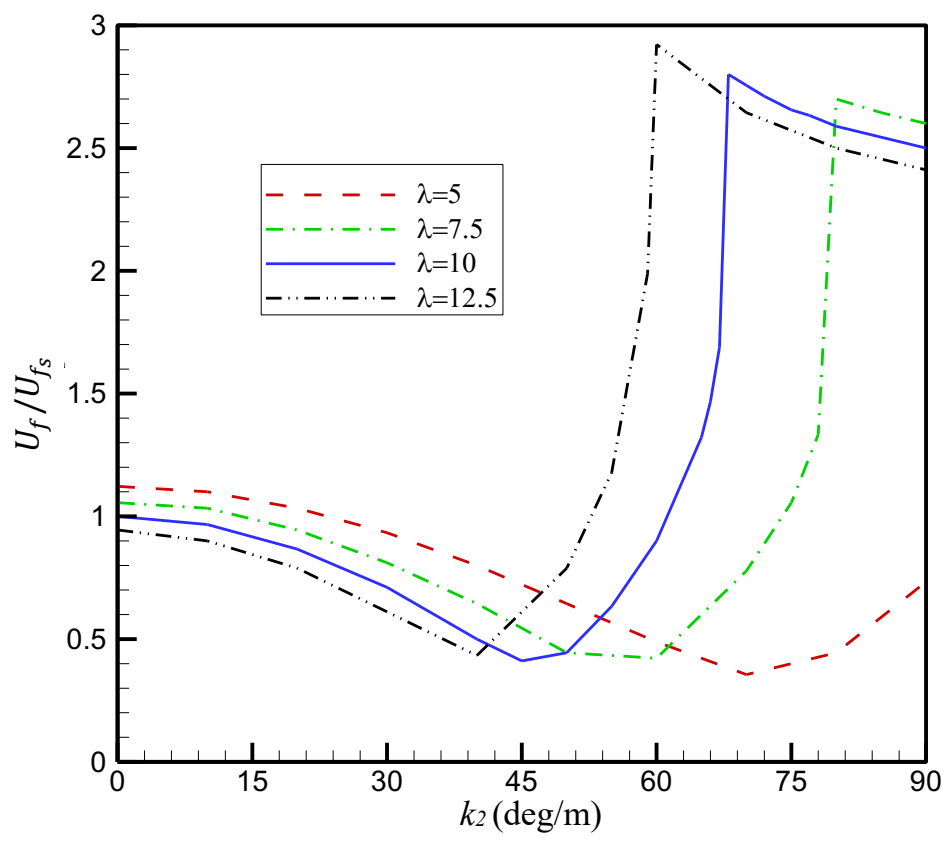

Figure 16: The effect of stiffness ratio, $\lambda$, on the flutter velocity for various initial curvatures. 


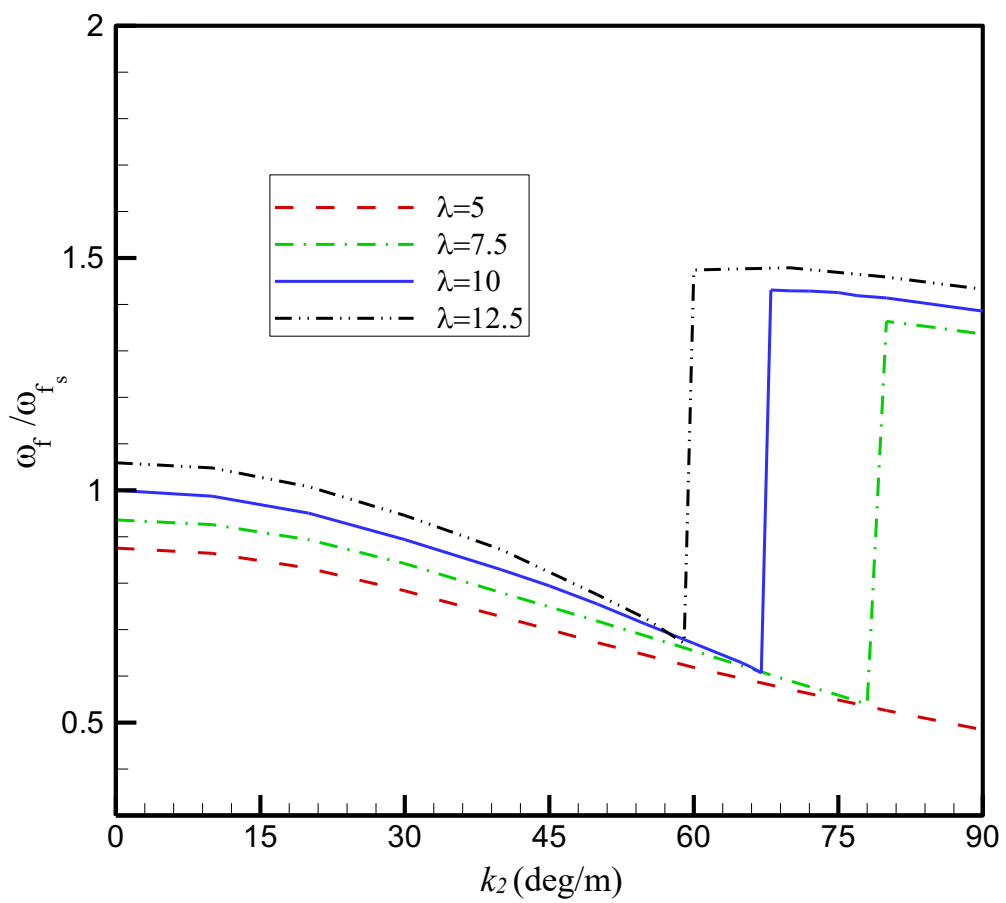

Figure 17: The effect of stiffness ratio, $\lambda$, on the flutter frequency for various initial curvatures.

Next, it is assumed that the wing is partly curved from the tip with a segment of length equal to $d l$, and the flutter stability of this partly curved wing is obtained. This case essentially resembles a wing with a curved winglet. The shape of the wing when different lengths of the wing are curved is shown in Figure 18 for $k_{2}=40 \mathrm{deg} / \mathrm{m}$. The flutter velocity of the wing when different lengths of the wing are curved, is determined and shown in Figure 19. Initially, when the curved segment length is smaller than $d l / L<0.3$, the flutter velocity of the wing doesn't change significantly. Then, when the segment length increases the flutter velocity decreases for all curvature angles, but then increases for two initial curvatures of $k_{2}=60$ and $80 \mathrm{deg} / \mathrm{m}$. 


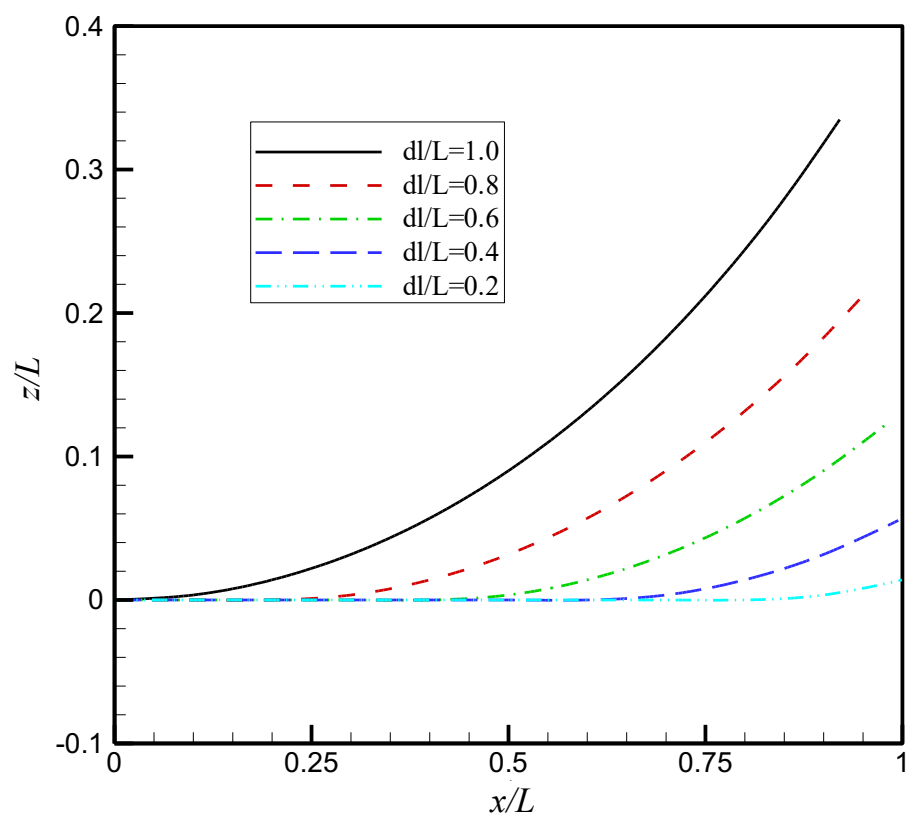

Figure 18: Partly curved wing configuration when the curvature angle is $k_{2}=40 \mathrm{deg} / \mathrm{m}$.

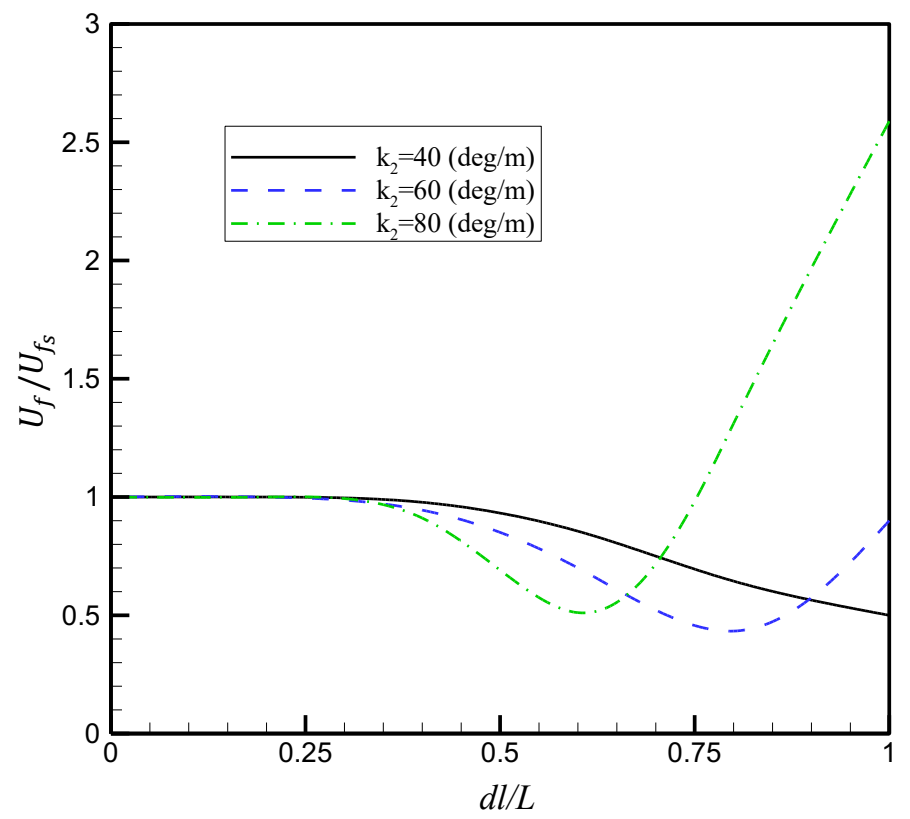

Figure 19: The flutter velocity of partly curved wing for various portion lengths.

In the final case, it is considered that the wing is partly curved from the root which is different to the previous case in which the wing was curved from the tip of the wing. The configuration of the wing on the ground for different segment lengths, $d l$, is shown in Figure 20 for $k_{2}=40 \mathrm{deg} / \mathrm{m}$. The flutter velocity of this wing is determined and plotted in Figure 21. In the case that the wing is curved from the root of the wing, for all of the initial curvatures, the flutter velocity 
decreases by increasing the segment length. When the initial curvature of the segment is $k_{2}=40 \mathrm{deg} / \mathrm{m}$, the flutter velocity of the wing gradually decreases, but for two other initial curvatures, the flutter velocity first decreases, and then increases. It must be noted that the trend of the change is totally different from the previous case that the wing was partly curved from the tip of the wing.

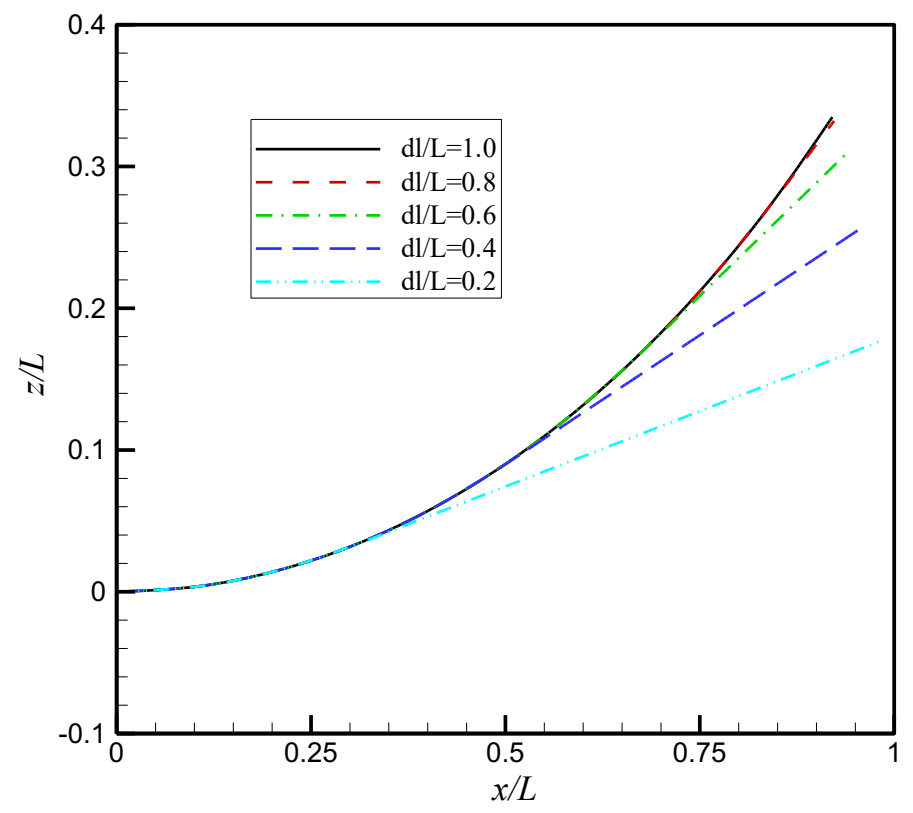

Figure 20: Partly curved from root configuration when the curvature angle is $k_{2}=40 \mathrm{deg} / \mathrm{m}$.

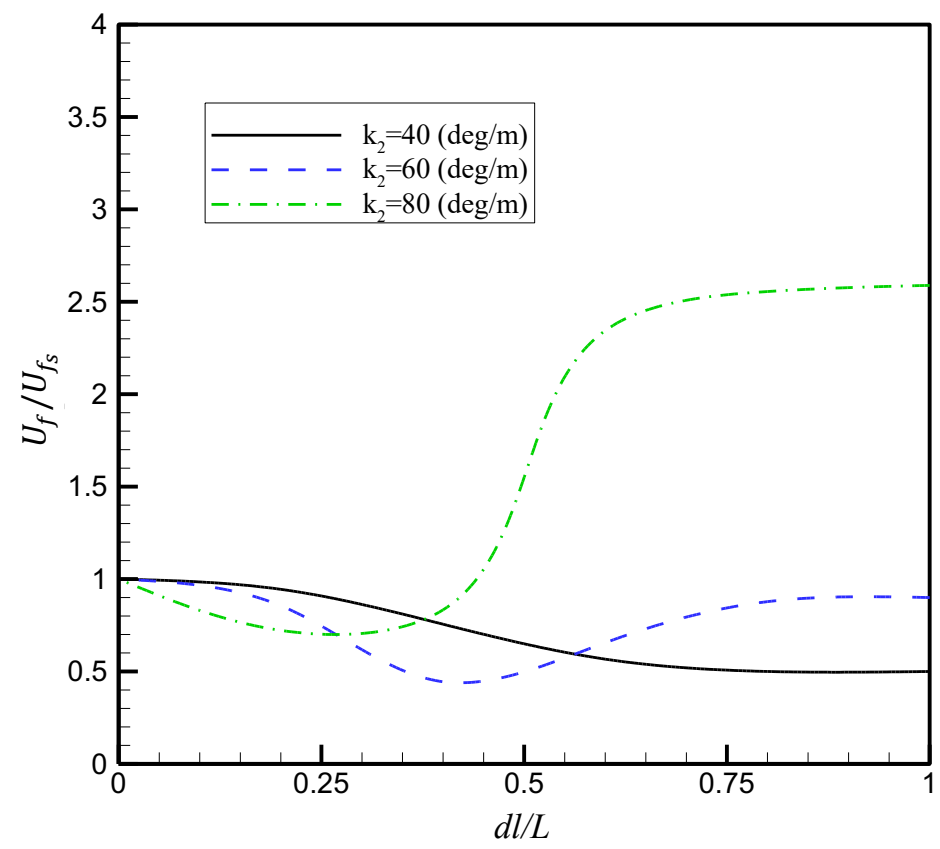

Figure 21: The flutter velocity of the wing partly curved from root versus various portion lengths. 


\section{Conclusions}

In this paper, the aeroelastic instability of a curved aircraft wing is investigated. The wing has an out-of-plane curvature which might have advantages in reducing the drag. The wing is modelled using the exact intrinsic beam formulation and the wing curvature is considered by adding the initial curvature to the beam formulations. The aerodynamic loads applied on the wing are modelled by using an incompressible unsteady aerodynamic model. The resulting aeroelastic equations are discretized through a second order accurate time-space scheme, and the aeroelastic stability of the linearized system is determined through an eigenvalue analysis. It has been shown that when the wing has an initial curvature, the wing dynamics are altered and the flutter velocity and flutter frequency change completely. Two case studies have been considered to study the effect of wing initial curvature. It has been shown that the constant perimeter case can result in better aeroelastic performance than the constant projected area case. By increasing the curvature value, the flutter velocity first decreases, and then sharply increases. This sudden jump in the flutter velocity and frequency is mainly due to the switching of the modes that contribute to the flutter mechanism. Initially, the first and second modes contribute to the flutter, whereas after a specific point the first and third modes couple to give instability. Furthermore, the wing stiffness ratio also influences the location at which the flutter mode switch happens. Finally, the aeroelasticity of partly curved wings has been considered. The length of the curved part of the wing was shown to significantly affect the flutter velocity and frequency and the location at which the flutter mode switch happens.

\section{References}

1. Bairstow, L., and Fage, A. "Oscillation of the taiplane and body of an aeroplane in flight," A.R.C. R. \& M. 276, part 2, 1916.

2. Goland, M. "The flutter of a uniform cantilever wing," Journal of Applied Mechanics Vol. 12, No. 4, 1945, pp. A197-A208.

3. Goland, M., and Luke, Y. L. "The flutter of a uniform wing with tip weights," Journal of Applied Mechanics Vol. 15, 1948, pp. 13-20.

4. Li, D., Zhao, S., Da Ronch, A., Xiang, J., Drofelnik, J., Li, Y., Zhang, L., Wu, Y., Kintscher, M., Monner, H. P., Rudenko, A., Guo, S., Yin, W., Kirn, J., Storm, S., and Breuker, R. D. "A review 
of modelling and analysis of morphing wings," Progress in Aerospace Sciences Vol. 100, 2018, pp. 46-62.

5. Barbarino, S., Bilgen, O., Ajaj, R. M., Friswell, M. I., and Inman, D. J. "A Review of Morphing Aircraft," Journal of Intelligent Material Systems and Structures Vol. 22, No. 9, 2011, pp. 823877.

6. Lottati, I. "Aeroelastic stability characteristics of a composite swept wing with tip weights for an unrestrained vehicle," Journal of Aircraft Vol. 24, No. 11, 1987, pp. 793-802.

7. Gern, F. H., and Librescu, L. "Static and dynamic aeroelasticity of advanced aircraft wings carrying external stores," AIAA Journal Vol. 36, No. 7, 1998, pp. 1121-1129.

8. Mazidi, A., and Fazelzadeh, S. A. "Flutter of a Swept Aircraft Wing with a Powered Engine," Journal of Aerospace Engineering Vol. 23, No. 4, 2010, pp. 243-250.

9. Goetz, R. C., and Doggett, R. V. "Some effects of tip fins on wing flutter characteristics," NASA TN D-7702, 1974.

10. Doggett, R. V., and Farmer, M. G. "Preliminary study of effects of winglets on wing flutter," NASA $T M X-3433,1976$.

11. Cui, P., and Han, J. "Prediction of flutter characteristics for a transport wing with wingtip devices," Aerospace Science and Technology Vol. 23, No. 1, 2012, pp. 461-468.

12. Lv, B., Lu, Z., Guo, T., Tang, D., Yu, L., and Guo, H. "Investigation of winglet on the transonic flutter characteristics for a wind tunnel test model CHNT-1," Aerospace Science and Technology Vol. 86, 2019, pp. 430-437.

13. Pecora, R., Amoroso, F., and Lecce, L. "Effectiveness of Wing Twist Morphing in Roll Control," Journal of Aircraft Vol. 49, No. 6, 2012, pp. 1666-1674.

14. Hunsaker, D. F., Montgomery, Z. S., and Joo, J. J. "Lifting-Line analysis of wing twist to minimize induced drag during pre roling moion," AIAA Scitech 2019 Forum, 2019. 
15. Rodrigue, H., Cho, S., Han, M.-W., Bhandari, B., Shim, J.-E., and Ahn, S.-H. "Effect of twist morphing wing segment on aerodynamic performance of UAV," Journal of Mechanical Science and Technology Vol. 30, No. 1, 2016, pp. 229-236.

16. Ismail, N. I., Zulkifli, A. H., Talib, R. J., Zaini, H., Yusoff, H., Sahari, B. B., Qin, Q., and Das, R. "Drag performance of twist morphing MAV wing," MATEC Web of Conferences 82, 01004, 2016.

17. Farsadi, T., Rahmanian, M., and Kayran, A. "Geometrically nonlinear aeroelastic behavior of pretwisted composite wings modeled as thin walled beams," Journal of Fluids and Structures Vol. 83, 2018, pp. 259-292.

18. Amoozgar, M. R., Fazelzadeh, S. A., Friswell, M. I., and Hodges, D. H. "Aeroelastic Stability Analysis of Tailored Pretwisted Wings," AIAA Journal Vol. 57, No. 10, 2019, pp. 4458-4466.

19. Fazelzadeh, S. A., Rezaei, M., and Mazidi, A. "Aeroelastic analysis of swept pre-twisted wings," Journal of Fluids and Structures Vol. 95, 2020, p. 103001.

20. Nguyen, N., and Urnes, J. "Aeroelastic Modeling of Elastically Shaped Aircraft Concept via Wing Shaping Control for Drag Reduction," AIAA Atmospheric Flight Mechanics Conference. 2012.

21. Chidamparam, P., and Leissa, A. W. "Vibrations of Planar Curved Beams, Rings, and Arches," Applied Mechanics Reviews Vol. 46, No. 9, 1993, pp. 467-483.

22. Hodges, D. H. "Non-linear inplane deformation and buckling of rings and high arches," International Journal of Non-Linear Mechanics Vol. 34, No. 4, 1999, pp. 723-737.

23. Chang, C. S., and Hodges, D. H. "Vibration characteristics of curved beams," Journal of Mechanics of Materials and Structures Vol. 4, No. 4, 2009, pp. 675-692.

24. Hodges, D. H. "Geometrically Exact, Intrinsic Theory for Dynamics of Curved and Twisted Anisotropic Beams," AIAA Journal Vol. 41, No. 6, 2003, pp. 1131-1137.

25. Peters, D. A., Karunamoorthy, S., and Cao, W.-M. "Finite state induced flow models. I - Twodimensional thin airfoil," Journal of Aircraft Vol. 32, No. 2, 1995, pp. 313-322. 
26. Amoozgar, M. R., and Shahverdi, H. "Aeroelastic Stability Analysis of Curved Composite Blades in Hover Using Fully Intrinsic Equations," International Journal of Aeronautical and Space Sciences, 2019.

27. Amoozgar, M. R., Shaw, A. D., Zhang, J., and Friswell, M. I. "Composite Blade Twist Modification by Using a Moving Mass and Stiffness Tailoring," AIAA Journal, 2018, pp. Accepted, DOI: 10.2514/1.J057591.

28. Amoozgar, M. R., Shaw, A. D., Zhang, J., and Friswell, M. I. "The effect of a movable mass on the aeroelastic stability of composite hingeless rotor blades in hover," Journal of Fluids and Structures Vol. 87, 2019, pp. 124-136.

29. Chang, C.-S., and Hodges, D. H. "Parametric Studies on Ground Vibration Test Modeling for Highly Flexible Aircraft," Journal of Aircraft Vol. 44, No. 6, 2007, pp. 2049-2059.

30. Fulton, M. V., and Hodges, D. H. "Aeroelastic stability of composite hingeless rotor blades in hover-Part II: Results," Mathematical and Computer Modelling Vol. 18, No. 3, 1993, pp. 19-35.

31. Mardanpour, P., Hodges, D. H., Neuhart, R., and Graybeal, N. "Engine Placement Effect on Nonlinear Trim and Stability of Flying Wing Aircraft," Journal of Aircraft Vol. 50, No. 6, 2013, pp. 1716-1725.

32. Mardanpour, P., Izadpanahi, E., Rastkar, S., Fazelzadeh, S. A., and Hodges, D. H. "Geometrically Exact, Fully Intrinsic Analysis of Pre-Twisted Beams Under Distributed Follower Forces," AIAA Journal Vol. 56, No. 2, 2017, pp. 836-848.

33. Amoozgar, M. R., and Shahverdi, H. "Analysis of nonlinear fully intrinsic equations of geometrically exact beams using generalized differential quadrature method," Acta Mechanica Vol. 227, No. 5, 2016b, pp. 1265-1277.

34. Amoozgar, M. R., Shahverdi, H., and Nobari, A. S. "Aeroelastic Stability of Hingeless Rotor Blades in Hover Using Fully Intrinsic Equations," AIAA Journal Vol. 55, No. 7, 2017, pp. 24502460. 
35. Amoozgar, M. R., Shaw, A. D., Zhang, J., Wang, C., and Friswell, M. I. "Lag-twist coupling sensitivity and design for a composite blade cross-section with D-spar," Aerospace Science and Technology Vol. 91, 2019, pp. 539-547.

36. Rivera, J. A. "Experimental and analytical investigation of the effect of spanwise curvature on wing flutter at Mach number of 0.7," NASA technical memorandum 4094, , 1989.

37. Smith, M., Patil, M., and Hodges, D. "CFD-based analysis of nonlinear aeroelastic behavior of high-aspect ratio wings," 19th AIAA Applied Aerodynamics Conference.

38. De Rosa, M. A., and Franciosi, C. "Exact and approximate dynamic analysis of circular arches using DQM," International Journal of Solids and Structures Vol. 37, No. 8, 2000, pp. 1103-1117.

39. Patil, M. J., Hodges, D. H., and Cesnik, C. E. S. "Nonlinear aeroelastic analysis of aircraft with high-aspect-ratio wings," 39th AIAA/ASME/ASCE/AHS/ASC Structures, Structural Dynamics, and Materials Conference and Exhibit. American Institute of Aeronautics and Astronautics, 1998.

40. Palacios, R., and Epureanu, B. "An Intrinsic Description of the Nonlinear Aeroelasticity of Very Flexible Wings," 52nd AIAA/ASME/ASCE/AHS/ASC Structures, Structural Dynamics and Materials Conference. 2011. 